\title{
Studies on Cystic Fibrosis Using Isoelectric Focusing. IV. Distinction between Ciliary Dyskinesia Activity in Cystic Fibrosis and Asthmatic Sera and Association of Cystic Fibrosis Protein with the Activity in Cystic Fibrosis Serum
}

\author{
GREGORY B. WILSON ${ }^{(40)}$ AND H. HUGH FUDENBERG \\ Department of Basic and Clinical Immunology and Microbiology, Medical University of South Carolina, \\ Charleston, South Carolina, USA
}

Summary

The cystic fibrosis protein (CFP) and ciliary dyskinesia activities (CDA) in sera from CF homozygotes, heterozygote carriers, and individuals with bronchial asthma have been partially purified. Concurrently, the CDA's in sera from patients with cystic fibrosis (CF) or bronchial asthma were shown to be different substances by ion-exchange or gel permeation chromatographic procedures. Sephadex G-200 chromatography indicated that the CF-CDA eluted with a protein fraction of molecular weight (MW) 68,000-150,000 and that the asthma CDA was found in a protein fraction of $\mathrm{MW}>\mathbf{1 5 0 , 0 0 0}$. The two activities coult also be separated by DEAE-cellulose chromatography. Prior acidification of whole normal, CF homozygote, obligate heterozygote, or asthmatic sera to pH 3.7 using EDTA, followed by fractionation on Sephadex G-200 removed all the CDA's from fractions of highermolecular weight and shifted the activities to a protein fraction of $\mathrm{MW} 1,100-13,700$. This procedure afforded a 200 . fold purification of the CDA's in sera from patients with asthma or CF. EDTA treatment, however, also generated a CDA in previously nonreactive normal sera. Subsequent fractionation of the various active G-200 fractions on Bio-Gel P10 allowed for the separation of three separate activities (Bio-Gel Fractions I, II-IV, and V). Fraction I was shown to represent the activity in sera from patients with asthma and was determined to be C3\& (MW 9,000). Fraction I was also found in normal, CF, and carrier sera and therefore is not a specific CDA. Fraction II-IV is thought to represent a CF-specific CDA (MW 5,000) since it could not be demonstrated in either normal or asthmatic sera but was found in sera of obligate heterozygotes. Fraction III-IV also did not react with antisera to human $C 3 a$. Fraction $V$ was generated from all serum types upon acidification of the serum with EDTA and is thought to be a nonspecific CDA. Bio-Gel P10 filtration of Sephadex G-200 fractions provided 823-fold and 650-fold puriication of the asthmatic and CF CDA's, respectively. Concurrent analysis of column fractions for CDA's by bioassay and for CFP by electrofocusing showed CFP only in fractions that contained the CF-CDA. Combined analyses employing acid disc gel electrophoresis, isoelectric focusing, and EDTA treatment of active CF-immunoglobulin (Ig) $G$ and Sephadex G-200 column fractions, followed by Bio-Gel P10 chromatography, provided evidence that CFP was associated with the CF-CDA. It is unknown as yet whether CFP itself is responsible for the CF-CDA activity.

\section{Speculation}

We have shown that the ability of CF $\alpha_{2}$-macoglobulin to modulate proteolytic enzyme activity is abnormal (22), and others have shown that polyamine metabolism is also abnormal in CF. We have recently shown that polyamines can inhibit $\alpha_{2}$ macroglobulin and proteinase enzyme functions $(24,25)$. We speculate that CFP and CF-CDA are both fragments of normal proteinases (proteinase analogs) bound to polyamines or polyamine derivatives and that the CFP-polyamine (or "CF factor"polyamine) complex is the effector substance responsible for ciliary dyskinesia in the rabbit system and partly responsible for the clinical manifestations of CF. Blockage of $\alpha_{2}$-macroglobulin and proteinase enzyme function by CFP-polyamine complexes or polyamines may give rise to the rest of the clinical manifestations in CF. 
INIROOUCTION

In a previous report (33) we described a modified version of the rabbit tracheal bioassay for the detection of cystic fibrosis (CF) ciliary dyskinesia factor (DDF). The assay was perfected to explore the possible biological activity of cystic fibrosis protein (CFP), previously found by us using electrofocusing $(27,30)$, and the relationship of CFP to the pathophysiology of
$\mathrm{CF}$ and to CDF. Our studies using whole sera indicated complete concordance CF and to CDF. Our studies using whole sera indicated complete concordance
between CFP positivity and ciliary dyskinesia activity (CDA) in all sera between CFP positivity and ciliary dyakinesia activity (CDA) in all sera CFP-negative and CDA-positive. Our results confirmed the earlier observation of Conover et al. (5) that when whole sera are bioassayed, sera from patients indistinguishable from the activity found in $C F$ sera.

our findings using combined electrofocusing and rabbit tracheal bioassay anal yses, however, suggested that the CDA found in patients with bronchial asthma may differ from a CF-specific CDF $(31,33)$. To test our hypoth
initiated purification of CFP and the CDAs in CF and asthmatic sera.

In the present study, CFP and the CDA in CF homozygote, CF heterozygote and asthmatic sera have been purified over 650-fold. The CDAs in CF and asthmatic sera were shown to be distinct by several chromatographic procedures. With each fractionation procedure employed, CFP was found only in
the fractions containing a CF-specific-CDA. Our results support our the fractions containing a CF-specific-CDA. Our results support our
suggestion $(31,33)$ that CFP is related to a CF-specific CDF. In addition we suggestion $(31,33)$ that CFP is related to a CF-specific CDF. In addition
have found evidence that the asthmatic CDA is C3a whereas the CF-CDA is not.

MATERIALS AND METHIODS

Collection and Processing of Samples

Serum samples obtained from clotted venous blood (33) were collected and processed for analysis by electrofocusing, bioassay, and fractionation procedures exactly as previously described $(32,33)$. The concentration of IgC in each sample and in individual column fractions (where noted in the Results) was measured by single radial immunodiffusion as previously described (27). The sera used in this study, with the exception of one from a presumed
heterozygote carrier for CF with bronchial asthma (see Results), were from the heterozygote carrier for CF with bronchial asthma (see Results), were from the
same individuals anal yzed previously by bioassay and electrofocusing $(28,32)$ The diagnoses of CF and bronchial asthma in all patients studied were made on the basis of the criteria previously noted (33). Informed consent was before blood was drawn.

Antigera

Antisera to human C3, IgG, and whole normal human serum were obtained from Meloy Laboratories, Springfield, VA. Antiserum to human C3 (anaphylatoxin) was obtained from Behring Diagnostics, Woodbury, NY, and from M. Michael Glov sky, M.D., Chief, Department of Allergy and Clinica
Immunology, Southern California Permanente Medical Group, Los Angeles, CA. Electrophoresis

Disc gel electrophoresis was performed in 158 polyacrylamide gel with acetic acid - $\beta$-alanine butfer, $\mathrm{pH} 4.5$, according to the procedure of Reisfield et al. (17), with the following modifications: (a) A large-por anti-convection gel was not used. Instead, samples were aplied in 208 (W/V) ( $N$, N-dial ytartardiamide; Pol ysciences, Warrington, PA) was used as a cross-1inker. The gel was stained and destained as aescribed for isoelectric focusing (IBF) (36). Samples were electrophoresed for approximately $1 \mathrm{hr}$ at 6 mA per gel using a Buchler electrophoresis apparatus (Buchler Instruments Inc., Fort Lee, NV). All disc gel electrophoresis and IEF experiments were
run at $4^{\circ} \mathrm{C}$ usiny a Lauca $k-\angle k$ controlled-temperature circulating water unit (Brinkman Instruments).

Immunoelectrophoresis at $\mathrm{pH} 8.6$ was performed by standard procedures using Veronol buffer $(\mathrm{r} / 2=0.1)$ (15). Immunoelectrophoresis at $\mathrm{pH} 4.5$ was run at $\mathrm{pH} 4.5$ were electrophoresed at a voltage setting of $100 \mathrm{~V}$ for $60 \mathrm{~min}$.

\section{Isoelectric Focusing}

IEF in disc gels (pH 3.5-10 gradient) was per formed by the method of Eder (8), as described previously (23), with the following modifications: (a) Gels of 108 acrylanide were used, and N,N-methylene-bisacrylamide was replaced by DATD as cross-1 inker (acrylamide:DATD ratio $1: 10$ ). (b) The anode and cathode
sol utions were 18 phosphoric acid and 18 TEMED to conform to the solutions solutions were 18 phosphoric acid and
used in thin-layer IEF $(29,21,27,39)$.

IEF in thin-layer pol yacrylamide gel was per formed using an LKB Multiphor electrofocusing apparatus (Model 2117-411 LKB, Brocma, Sweden) by modification
of the procedures described previously $(22,23,27)$. The complete methodology of the procedures described pre
is described elsewhere $(20,32)$.

Reading of the $\mathrm{pH}$ gradient and fixing, staining, and destaining of the gel were performed as described previously (27) with minor modification (20). An example of the $\mathrm{pH} 2.5-16$ gradient as measured at $4^{\circ} \mathrm{C}$ on the surface of the gel is shown in Figure 1 . All whole serum samples were analyzed using a
vol ume of serum standardized to contain $300 \mu$ of IgG $(27,32)$. Serum fractions obtained by chromatography were analyzed using the amounts indicated (see Results).

\section{Ion-Exchange Chromatography, Gel Filtration, and Ultrafiltration}

Fractionation of sera on DEAE-cellulose (DE-52, Whatman) was performed using either $0.01 \mathrm{M}$ phosphate (pH 8.0) or $0.005 \mathrm{M}$ Tris-HCl $(\mathrm{pH}, 8.6)$ buffer and
a discontinuous step gradient of $\mathrm{NaCl}(0.08 \mathrm{M} ; 0.05 \mathrm{M}, 0.1 \mathrm{M}, 0.2 \mathrm{M}$ ) as described previously $(23,26)$ without EDTA. Gel filtration on Sephadex 6268 (Pharmacia) was conducted as previously described (26) using 0.01 M phosphate ouffer, pH 8.8 with $15 \mathrm{M} \mathrm{NaCl}$ (PBS, pH 8.6) for elution. Gel filtration on col um at a flow rate of $5 \mathrm{ml} / \mathrm{hr}$. Fractions of $2.0 \mathrm{ml}$ were collected and PQS was used for el ution. For EDTA treatment, whole sera or fractions were mixed with solid EDTA (Fisher) to saturation (pt 3.7) and left at room temperature for $15-20 \mathrm{~min}$. Sephadex $\mathrm{G} 200$ and Bio-Gel

All column fractionations were performed at $4^{\circ} \mathrm{C}$ using siliconized glass col umns and plastic tubes. Fractions were pooled, dialyzed using spectrapor 3 dial ysis membrane tubing (MW retention 3500; Spectrum Medical Industries, Los
Angeles, CA) to equilibrium against $0.8025 \mathrm{M}$ phosphate, pt 7.2, ank lyophilized, Fractions were reconstituted in distilled water and redialyzed if found to contain excessive electrolytes. Sephodex G200 Fraction I (MW $>200,000, V_{\theta}$ as shown in Results) from CF serum was alpo concentrated by Amicon ultrafiltration over a UM-2 membrane (MN retention 1008; Amicon Corp.. Lexington, MA) to exclude the possibility that lyophilization cold have
destroyed any activity. Spock et al. (19) have previously reported that this fraction contains ciliary dyskinesia activity.

The protein concentration in different fractions was estimated by reading the absorbance at $280 \mathrm{~nm}$ and/or $228 \mathrm{~nm}$. Exact anounts of protein were (13).

Isolation of Human C3a (Anaphylatoxin)

Anaphylatoxin was isolated from human plasma according to the methods of Hugli et al. (10). The final preparation reacted with antisera to human C3a but not to C3 nor with antisera to a variety of other hunan serum proteins after electrophoresis at pH 4.5 , and was of M
chromatography on a calibrated Bio-Gel plo column.

Bioassay

Determinations of CDA in whole sera and column fractions were performed as described previously for whole sera (33). All fractions (in 0.01 M $37^{\circ} \mathrm{C}$ just prior to bioassay (33). The protein concentration of the fractions tested by bioassay or analyzed by other methods is given as the concentration relative to the original starting material (whole serum equals ix concentration), unless otherwise indicated. Samples were considered positive if they produced ciliary dyskinesia prior to $45 \mathrm{~min}$. However, it should be noted that some samples were also ciliotoxic (not due to excessive electrolytes),
majority of the samples tested reacted by $35 \mathrm{~min}$ at a $1 \mathrm{x}$ concentration.

RESULTS

Distinction between CFP, CF-CDA, and Asthnatic CDA

Whole human serum. Previous comparative anal yses of whole sera for CFP and CDA positivity indicated complete agreement between the presence or atsence of these two markers for CF in all sera tested, except for patient

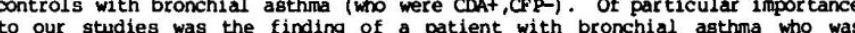
CFPt,CLA+ (Table 1). This individual provided us with a unique opportunity to study a presumed heterozygote for $\mathrm{CF}$ with confirmed bronchial asthma.

DRAE-cellulose chromatography. Anal ysis of fractions from DEAE-cell ulose chromatography demonstrated that CFP was present only in the IgG-containing fractions (Tahle 2, Figs. 2 and 3). When phosphate buffer was used, the CDAs in CF and asthmatic sera were both found in Fraction I with CFP. When Tris-HCl buffer was used, CFP and the CF-CDA were separated from the asthmatic
CIA, the latter being found in Fraction II. The asthmatic presumed CIA, the latter beiny found in Fraction II. The asthmatic presumed
heterozygote carrier presented two activities, one with CFP in Fraction I and heterozygote carrier present
the other in Fraction II.

Use of Tris-HCl Duffer thus afforded one method for disting uishing between CP-CDA asthmatic coA, and sugded of with $\mathrm{CF}-\mathrm{CDA}$. Of particular interest with regard tis the Fraction I contains only those serum proteins with the most basic pI values (last $\mathrm{cm}$ of stained banding pattern) (Figs. 2 and 3 ). Immunoelectrophoresis of serum Fractions I and II eluted with either phosphate or Tris-HCI buffer showed that phosphate Fraction I contained only IgG and that Tris-HCl Fraction
I contained only the most cathodal IgG proteins (Fig. 3a,d-h). However, we I contained only the most cathodal IgG proteins (Fig. $3 a, d-h$ ). However, we
cannot exclude the possibility that other serum proteins which may not react with antisera to normal human serum could be present in Fraction I. Fractions obtained from CF homozygote, CF heterozygote, asthmatic, and normal sera
showed similar patterns after immunoelectrophoresis, regardless of whether they were positive or negative for CFP or CDA.

Sephadex gel filtration. Fractionation of all serum types oy gel iltration with $2 \mathrm{~mL}$ of serum is shown in Figure A typical chromatogram obtained (reconstituted to $1 \mathrm{x}$ protein concentration) showed that the CDA in CF sera was contained in Fraction III and in Fraction IV (weak CDA) and was distinct from asthmatic CDA, which was found only in Fraction II (Table 3). Sephadex G200 Fraction I from CF sera, whether lyophilized or concentrated by ultrafiltration, failed to elicit a CDA response. The activities in Sephadex G290 Fractions II, III, and IV and in DEAE-cellulose Fractions I and II were all stable to Iyophilization. The asthmatic/heterozygote serum showed

any fraction. CFP was present only in Fraction III. Representative results from electrofocusing of G200 Fractions II and III from CF homozygote, heterozygote, can be seen only in G2BB Fraction III from the CF homozygote and heterozygote samples.

Analysis of Fractions II and III from $C F$ serum by immunoelectrophoresis is shown in Figure $3 \mathrm{~b}$ and $\mathrm{c}$, to illustrate the number and relative amount of serum proteins found in each fraction. IgG (large cathodal band) and C3 were
found in both fractions by separate analyses using specific antisera (not shown.

Treatment with EYTA. Previous studies have shown that most of the CPP is separated from the bulk of the serum proteins by pretreatment of whole CP serum with $10 \mathrm{mM}$ EDTA, followed by Sephadex G200 gel filtration (23). Subsequent experiments indicated that increasing the EDTA concentration to separation. Therefore, the effect of EDTA on the CDAs in asthmatic and CF separation. Therefore, the effect of EDTA on the CDAs in asthmatic and CF
sera was tested. Treatment with EDTA prior to gel filtration routinely eliminated all CDA activities in Fractions II-IV and generated a cDA (in all gera) found excl usively in Fraction VI (WW 1,108-13,700; Fig. 4) (Table 3).
Analysis of Fraction VI (6.7 mg/ml) (obtained with or without prior EDTA Analysis of Fraction VI (6.7 mg/ml) (obtained with or without prior EDTA treatment) by immunoelectrophoresis at pH 8.6 against antiserum to whole human immunoelectrophoresis was a single anodal arc, which was identified as albumin, in one G200 Fraction VI from normal serum.

Analysis of Fraction VI $(25 \mu \mathrm{g})$ by acid disc gel electrophoresis, however, showed the presence of several cathodal bands and indicated obvious Jifferences between the serum types (Figs. 6 and 7 ). In particular, an extra
cathodal band was noted in sephadex G208 Fraction VI from CF and carrier 
samples (Fig. 6), and two additional cathodally migrating bands were noted in normal or asthmatic samples (Fig. 7).

Electrofocusing indicated that Fractions I-V from EDTA-treated sera of all types were negative for CFP, and that CFP was not generated in normal control or asthmatic sera by EDTA treatment. Figure 8 illustrates the results of analysis of CF G2BB Fraction III by electrofocusing before and after EDTA treatment of an otherwise identical serum sample. Note that no bands are found opposite the marker after EDTA treatment of CF serum followed by of CFP before and after EDTA treatment (Fig. 8). EDTA treatment did not destroy CFP, which was still present when EDTA-treated whole sera from CF homozygotes or heterozygotes were electrofocused (not shown). This finding,
and the occurrence of an additional band in G200 Fraction VI from homozygote and the occurrence of an additional band in G200 Fraction VI from homozygote and heterozygote sera after EDTA treatment (Fig. 7), suggest that dissolution
of a CFP-IgG (or other precursor) complex occurs upon acid treatment, and that of a CFP-IgG (or other precursor) complex occurs upon acid treatment, and that
subsequent chromatography separates the CFP and CDA from larger macromolecules in $\mathrm{CF}$ and asthmatic sera.

Partial direct confirmation of the movement of CFP to Fraction VI was obtained by disc gel IEF. As shown in Figure 9, banding differences were evident then equal mounts (25 pg) of Sephadex G200 Fraction VI from EDTA-treated normal and CF sera were analyzed. Bands near pH 8.5 were evident
in the CF sanple. Disc gel IEF and acid electrophoresis added further evidence for the association of CFP and several other cationic proteins with the activity in Sephadex G200 Fraction VI from CF homozygote or heterozyte EDIA-treated sera. However, these data do not explain the generation of CDA
in normal sera or its movement from Fraction II to VI in asthmatic sera after EDTA treatment.

\section{Bio-Gel P10 Filtration}

Analysis of G200 Fraction VI from EDTA-treated samples (from $2 \mathrm{ml}$ of serum) by gel filtration on Bio-Gel P1Q is shown in Figure 16 , which is a composite for all fractionations on Bio-Gel PlQ. Subfractionation of Sephadex G200 Fractions II, III, and IV or of IgG yielded peak A and the other peaks shown. (Bio-Gel Plo excludes molecules of MW $>29,60 \theta$.) Peak A corresponds to
molecules of $M W>26,090$ eluted in the void volume ( $V_{B}$ or Peak A). Bioassay of the Bio-Gel Plo subfractions indicated the existence of three separate activities, in Peaks I, III-IV, and V (Table 4) in CF homozygote an heterozygote G200 Fraction VI, but only two in normal and asthmatic samples. 5000), since it could not be demonstrated in analogous fractions from normal or asthmatic sera.

Chromatographic analysis of CF-IgG (DEAE-cellulose Tris-HCl Fraction I) and CF G206 Fractions III and IV with and without EDTA treatment indicated derived from IgG or another macroglobul in-CDA complex. Without treatment, all the CDA found in Sephadex G208 Fractions III and IV or with IgG eluted in Peak $A$, whereas prior treatment with EDTA effectively disassociated the activity. Figure 8 shows the results of electrofocusing CF DEAE-cellulose Fraction I
(Tris-HCl), which was eluted from Bio-Gel Plo before (C) or after (C-EOTA) pretreatment of the sample with EUl'A. When equal amounts of the same fraction
were anal yzed, DEAE-cellulose fraction I obtained from Bio-Gel plo fraction A were analyzed, DEAE-cellulose Fraction I obtained from Bio-Gel P10 Fraction A
pretreated with EDTIA (as compared with the untreated fraction) was devoid of the CFP doublet. This finding indicates that CFP is disassociated from the IgG fraction and elutes with molecules of lower MW a
is unknown at present in which fraction CFP is found.

Pretreatment of normal G200 Fractions III and IV with EDTA showed that both the activities found in Sephadex G200 Fraction VI from EDTA-treated normal serum originated from these G200 fractions (Table 4). Pretreatment of normal or asthmatic Sephadex G20y Fraction II with EDTA also resulted in
subseguent el ution of one of the peaks of activity (Fraction I). These data suggest the possibility that sone macroglobulin or a complex found in rormal. activities in Bio-Gel Pld Fractions I and $V$ after treatment of the Sephadex G200 fractions with EDTA.

al. (6) had previously suggested that C3a might be responsible for the et al. (6) had previously suggested that C3a might be responsible for the CDA activity in CF and asthmatic sera, we screened representative active samples
of Bio-Gel PIQ Fractions I-VI for C3a by immunoelectrophoresis at pH 4.5 using a potent rabbit antiserum to human C3a. In previous experiments employing this antiserum and hunan C3a purified by the method of Hugli et al. (10). a reaction could be observed when as little as $25 \mu \mathrm{ll}$ of a $0.25-\mathrm{mg} / \mathrm{ml}$ solution of Cra was anal yzed. Anal ysis of concentrated preparations of the Bio-Gel P16 presence of $\mathrm{C} \mathrm{a}$ in any fraction other than Fraction I. Since only Fraction I from Bio-Gel P19 gel filtration of EDTA-treated
asthma G20日 Fraction II showed activity (and only G20日 Fraction II was active from asthmatic sera), we conclude from these preliminary findings that the CDA in asthmatic sera probably is attributable to C3a. It is not surprising that the activity in Bio-Gel P1ब Fraction I could be el uted from either EDTA-
treated G2ø日 Fractions III+IV (combined) or Fraction II, since analysis of treated G200 Fractions III+IV (combined) or Fraction II, since analysis of
these G269 fractions by immunodiffusion indicated the presence of C3. It is these $\mathrm{G} 26 \mathrm{~g}$ fractions by immunodiffusion indicated the presence of $\mathrm{C3}$. It is
known that acid conditions favor the dissolution of $\mathrm{C} 3 \mathrm{a}-\mathrm{C} 3 \mathrm{~b}$ complexes (see known that acid
References in 10).

Regardless of the identity of the activity in Bio-Gel P16 Fraction I, the results in Table 4 clearly indicate the existence of a unique CDA activity derived from $C F$ homozygote and heterozygote sera (Bio-Gel P10 Fraction III-IV) and suggest that Sephadex G200 gel filtration followed by Bio-Gel P1b. Current research in this laboratory is directed toward the bulk purification and complete characterization of the components responsible for the CDA in Bio-Gel P10 Fractions I, III-IV, and V.

Table 5 surmarizes the extent of purification of the CDAs in CF and asthmatic sera obtained by Sephadex G200 and Bio-Gel P10 gel filtration. The
data in Table 5 are based on two assumptions: (a) that there is no loss of activity during purification, and (b) that a "unit" of ciliary dyskinesia activity can be defined as the amount of activity per mg protein present in a IX concentrated preparation. Treatment of CF or asthmatic sera with EDT the specific activity present in whole serum. When Sephadex G200 Fraction VI was fractionated on Bio-Gel P18, the asthmatic CDA (G200 Fraction II)
purified 823-fold and the CF-CDA 650-fold (Bio-Gel P10 fraction III-IV).
DIsaussion

Spock et al. (19) originally described a factor (now termed "ciliary dyskinesia factor" or CDF) that was present in the serum of both homozygotes and heterozygotes for $\mathrm{CF}$ and produced dyskinesia of the ciliary beat in (19) was felt by them to be a specific marker for the CF gene, since the CD was not found in sera from patients with a variety of respiratory and autoimune disorders and
a family history for $\mathrm{CF}$.

The CDF was characterized by Spock et al. (19) as a nondial yzable, heat-labile $\left(1000^{\circ} \mathrm{C}, 1 \mathrm{~min}\right)$ serum activity associated with the euglobul in fraction. Gel filtration of CF homozygote serum on Sephadex G200 produced two found with the proteins excluded from the gel and el uting in the void vol une. The other activity (Fraction IV) was associated with serum proteins eluting between IgG (NW 150,000) and albumin (NW 68,006$)$ (19).

Conover et al. (4-6), and more recently wilson et al. $(20,33,34)$, have confirmed and extended the original observations of spock et al. concerning the presence of a CDF in sera from homozygotes and heterozygotes for CF (19) Although both groups of investigators could detect a ciliary dyskinesiary
activity (COA) in whole sera from both CF genotypes and not in sera from activity (COA) in whole sera from both CF genotypes and not in sera from
normal healthy controls, Conover et al. (5) found that sera from normal normal healthy controls, Conover et al. (5) found that sera from normal
patient controls with a variety of autoimmune and respiratory diseases produced a ciliary dyskinesia reaction indistinguishable from the reaction caused by sera from CF homozygotes. The finding of a CDA in sera from patients with certain respiratory and autoimume disorders led conover et al. (5) to suggest that such individuals and CF patients share some functional or structural abnormality in their complement system. The findings of conover et al. $(5,6)$ seemingly confirmed and extended the original hypothesis of wilson and Jahn $(28,29)$, who had previously suggested "that CF may have as one of its characteristics a complement related deficiency", manifested as "altered complement components or fragments of normal intact complement components synthesized and excreted into the humoral fluids" (28). Wilson and Jahn felt
that the abnormality in complement in CF could be due to an alteration in
normal complement function caused by an abnormality either in a complement nomal complement function caused by an abnormality either in a complement
component inactivator or in an initiator of the alternate complement pathway $(9,28)$.

Subsequently, Conover et al. (6) presented eviaence suggesting that the elusive CF-CNF was C3a (anaphylatoxin) and proposed that a defect or deficiency in the anaphylatoxin inactivator (a carbox ypeptidase-B-like enzyme) was the primary genetic defect in CF. In addition, Polley and Bearn (16) proactivator to $C$ activator and $C 3$ to its hemolytically inactive product (Ci); both results were suggestive of a possible derangement in the alternate

In the present report our results (Tables 2 and 3 ) show that the CDA in asthmatic sera elutes in column fractions different from the CDA found in sera from homozygotes and heterozygotes for CF. Fractionation of all serum types on either DEAE-cellulose (an ion-exchange resin) or Sephadex G200 indicated and of higher MW than the CF-CDA or a CFresults from Sephadex 6200 gel filtration of CF serum agree in part with thos of Spock et al. (19), since both of us found a CF-CDA in a serum protein
fraction of 68 , 660 - 156,060. Unlike Spock et al. (19), however, we could fraction of $68,660-150,060$. Unlike Spock et al. (19), however, we could
not denonstrate a CDA in Fraction I from sephadex (200 (Fig. 4, Table 3) when not demonstrate a CDA in Fraction I from sephadex G200 (Fig. 4, Table 3) when
concentrated by either lyophilization or ultrafiltration. We cannot at concentrated by either lyophilization or ultrafiltration. We cannot at
present explain the discrepancy between the findings of Spock et al. (19) and our own, especially since the CF-CDA in Fractions III and IV is stable to lyophilization and is not lost during concentration
ultrafiltration over a UM-2 membrane (data not shown).

The possibility that the asthmatic $\mathrm{CDA}$ and $\mathrm{CF}-\mathrm{CDA}$ could be the same substance possibly bound to different carriers in asthmatic and CF sera is no excluded by our finding of all CDA-containing fractions in serum from a
presumed heterozygote carrier with asthna (Tables 2 and 3 ). Our data indicate that this serum had all the fractions with activity (DEAE Fractions I and II, G260 Fractions II, III, and IV) but do not permit a conclusion as to whether macroglobulins with which the same cDAs complex.

Our studies using EDTA treatment prior to Bio-Gel Ply gel filtration, however, strongly indicated that the two CDAs are not structurally the same ('Table 4). The asthmatic CDA (Bio-Gel PlG Peak I) was of MW -9606, reacted with antiserum to human $\mathrm{C} 3 \mathrm{a}$, and could be derived from either normal or On the other hand, a CDA specific to CF sera separated from other nonspecific CDAs on Bio-Gel P10 and was found in Bio-Gel ple Fraction III-IV (MW - 5000; Fig. 9) (Table 4). Bio-Gel p16 Fraction III-IV did not react with antiserum to human C3a, and the CDA could
Fraction II or III-IV (Table 4).

Our findings suggest, therefore, that a CDF does exist in sera from homozygotes and heterozygotes for $\mathrm{CF}$ which may be specific for the CF gene. Unlike the CDA described by Conover et al. (6), our CF-CDA does not seem to be normal intact $\mathrm{C} 3 \mathrm{a}$ and does not require IgG for activity (Tables 3 and 4). We
are currently exploring the possibility that the CF-CDA may be a fragment of C3a or even possibly C5a or c2-kinin.

of related interest are the results of Bownan and co-workers $(2,3)$ concerning the specificity and identification of a ciliotoxic factor (CTF) found in sera from homozygotes and heterozygotes for CF. The CTF, which is detected using an oyster gill ciliary bioassay (12), has a Mw, cationic charge, and other properties which resenble those of the CDF described by Conover et al. (6). Barnett and Bownan (1) claim, however, that the CTF is
specific for CF, is not C3a, and does not require IgG for activity $(2,7)$. specific for CF, is not C3a, and does not require IgG for activity $(2,7)$.
These properties distinguish CTF from the CDF of conover et al. (6) but These properties distinguish CTF from the CDF of conover et al.
suggest a close relationship to the CF-CDF described in this report.

Disagreement between our results and those of Conover et al. (17) might best be explained by comparing the techniques used to isolate the CDA CDF from other macromolecules. We used acidification of whole serum, Sephadex G200 fractions, or purified IgG-CDA complexes followed by gel filtration on Bio-Gel Plo to separate the CDAs. As our data show (Fig. 9, Table 4), C3a, $1,080-10,000$ and could never be separated using the ultrafiltration methods of conover et al. 
Since our data (Table 4) indicate that the CF-CDA (Bio-Gel Peaks III-IV) and the C3a activity (Peak I) can both be derived from CF-IgG and CF G200 Fraction III+IV, it is tempting to suggest that Conover et al. (6) may have detected only the C3a activity and either missed the CF-specific CDA or
destroyed it during execution of the experiments they described (6).

The CFP detected by isoelectric focusing $(26,23,27,32)$ was previously sugpested to be related structurally or metabolically to a CF-specific CDF (33). Our findings in this study indicate that all fractions which contain 4r-con aiso contaln crp and support our proposal. we have been unable to determine as yet whether the CFP protein Itself is responsible for the activity in Bio-Gel Fraction III-IV; however, we have presented evidence that both the CPP and the CP-CDA are removed fram CF-IgG and CF G200 Fraction III after pretreatment of the fraction with EDTA followed by gel filtration on
Bio-Gel p10 (Fig. 8). In addition, acid disc gel electrophoresis and isoelectric focusing (Figs. 6,7 and 9 ) of active frections indicate that an additional cationic protein band is present in CF G200 Fraction VI from EDTA-treated serum, and that several proteins with pIs near pH 8.5 are present in this same fraction. Analogous fractions from heterozygote carrier se
but not from asthmatic sera, also showed all these cationic protein bands.

\section{CONCWUSION AND SUNAARY}

The results of this investigation provide evidence that sera from homozygotes and heterozygotes for CF harbor a unique cilliary dyskinesia chive distinct from a cDA found in sera from patients with bronchial asthma. furtinet from a COA found in sera from patients with bronchial asthma. the CF-CDA is not, since fractions which contain 8eb-fold purified asthmatic CDA react with antiserum to C $3 a$, whereas fractions containing 650-fold purified CF-CDA do not (Table 5). Although the results of this study add evidence for our suggestion that CFP may be the CF-specific CDA, further purification of CFP and the CF-CDA will be required to determine
specific protein band with a PI near pH 8.5 (CFP) 18 the CF-CDA.

The identities of our CFP and CF-CDA and the CTF described by Bowman and co-workers $(2,7)$ remain unknown. Although they are not normal C3a, it is atill possible that these elusive "CF factors" could be related to some defects are evident in CF serum $(16,28,29)$. Of direct relevance to the above

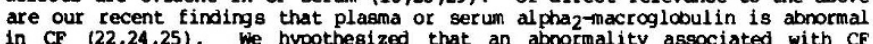
in CF $(22,24,25)$. We hypothesized that an abnormality associated with CF alpha 2 -macroglobulin can explain the presence of "CF factors" (whatever their carriers, as well as much of the pathophysiology of the disease, since a generalized failure of CF homozygote (and to a lesser extent heterozygote) alpha - -macroglobulin to regulate or modulate serum proteinases such as plasmin
or kallikrein could lead to the excessive production of C3a, kinins, and other substances which can alter membrane permeability and electrolyte transport
$(22,24,25)$. Our hypothesis of a defect in interactions between alpha $2^{-m a c r o g} l o b u l i n$ and proteol ytic enzymes in CF has been confirmed recently by Shapira et al. (18). It is also known that "CF factors" are produced by wite cells and fibroblasts in culture (7) and that alpha 2 -macroglobulin is a mentiare (14).

Pecent research in this laboratory has been directed at extending our findings to determine (a) whether the structure and/or function of cell

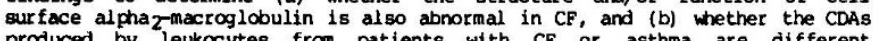
produced by leukocytes from patients with CF or asthma are different subatances (34). We have also been exploring our proposal of a possible relationship between an abnormality in polyamine retabolisin in CF and defective proteinase regulation by $\mathrm{CF}$ alphaz-macroglobulin (22). We have
recently shown (a) that the CDA produced by leukocytes from individuals who recently shown (a) that the CDA produced by leukocytes from individuals who
harbor the CF gene is distinct from the CDA synthesized by leukocytes from harbor the $\mathrm{CF}$ gene is distinct from the CDA synthesized by leukocytes from
individuals with bronchial asthma (34,j)), (b) that polyamines can differentially markedly inhibit the function of al pha $2^{\text {-macroglobulin and }}$ may be structuraliy abnormal proteinase analogs and/or complexed to a may be structurally $y$ abrormal

In a future report (24) we clarify the relationship of our findings to the primary genetic defect in CF responsible for the above metabolic abnormalities and other "geemingly unrelated" defects in metabolism observed cells and humoral fluids are studied in vitro.

\section{REFERENCES AND NOTES}

1. Barnett, D.R., and Bownan, B.H.: Cystic fibrosis ciliary inhibitor Pediat. Res., 8:687 (1974)

2. Bownan, B.H.: Factors related to cystic fibrosis. in: J.A. Mangos and R.C. Talamo: Cystic Fibrosis: Projections into the Future.
(Stratton Intercontinental Medical Book Corp.. N.Y., 1976).

3. Bowman, B.H., Lockhart, L.H., and McCombs, M.L.: Oyster ciliary

4. Conover, J.H., Bonforte, R.J., Hathaway, P., Pacinc, S., Conod, E.J. Hirschhorn, K., and Kopel, F.B.: Studies on cillary dyskinesia factor in cystic fibrosis. I. Bioassay and hetero zygote detection in serum. Pediat. Fes., $\underline{7}: 226$ (1973).

5. Conover, J.H., Conod, E.J., and Hirschhorn, K.: Ciliary dyskinesia factor in immunological and pulmonary disease. Lancet, $\underline{i}: 1194$ (1973).

6. Conover, J.H., Conod, E.J.., and Hirschhorn, K.: Studies on ciliary dyskinesia factor in cystic fibrosis. IV. Its possible identification as onaphy latox in (C3a) -IgG complex. Life Sci..14:253 (1974).

7. DiSant Agnese, P.A., and Davis, P.B.: Research in cystic fibrosis. New Eng. J. Med., 295: 534 (1976).

8. Bder, J.: Isoelectric focusing of antibodies in polyacrylamide gels. J. Inmunol Meth., 2:67 (1972).

9. Gemur z, H.: Alternate pathways to activation of the complement system. in: D.G. Ingram: Biological Activities of Complement. p. 56 (S. Karger, N.Y., 1972)

18. Hugli, T.E., Vallota, E.H., and Muller-Eberhard, H.J.: Purification and partial characterization of human and porcine C3a anaphylatoxin. J. Biol. Chen., 250:1472 (1975).

11. James, K., Tunstall, A.M., Parker, A.C., and McCormick, J.N.: The association of al pha 2 -macroglobulin with lymphocyte membranes in chronic 1 ymphocytic leukenia and other disorders. Clin. Exp. Immunol., 19:237 (1975).

12. Lockhart, L.H., and Bowman, B.H.: Assay for detection of the cystic fibrosis gene. Tex. Rep. Biol. Med., 31:631 (1973).

13. Lowry, О.H., Rosebrough, N.J., Farr, A.L., and Randall, R.J.: Protein (1951).

14. Monsher, D.F., and Wing, D.A.: Synthesis and secretion of alpha ${ }_{2}$-macroglobulin by cultured human fibroblasts. J. Exp. Med. $143: 462(1976)$.

15. Ouchter lony, O., and Nilsson, L.A.: Immunodiffusion and immunoelectrophoresis. in: D.M. Weir: Handbook of Experimenta Immunology. p. 191 (Blackwell Scientific Publications, London, 1974).

16. Polley, M.J., and Bearn, A.G.: Cystic fibrosis, current concepts. J. Med Genet., $\underline{11}: 249,1974$.

17. Reisfeld, R.A., Lewis, V.J., and Williams, D.E.: Disk electrophoresis of basic proteins and peptides on polyacrylamide gels. Nature, 195:281 (1962).

18. Shapira, E., Rao, G.J.S., Wessel, H.U., and Nadler, H.L.: Absence of an $10: 812$ (1976).
al pha -mocroglobul in-protease complex in cystic fibrosis. Pediat. Res.,
(19)

19. Spock, A., Heick, H.M.C., Cress, H., and Logan, W.S.I Abnormal serum factor in patients with cystic fibrosis of the pancreas. Pediat. Res., $\underline{1}: 173$ (1976)

2y. Wilson, G.B., Arnaud, P., and Fudenberg, н.H.: An improved method for the detection of cystic fibrosis protein in serum using the LKB multiphor
electrofocusing apparatus. Pediat. Res., 11: in press (1977).

21. Wilson, G.B., Arnaud, P., Monsher, M.T., and Fudenberg, H.H.: Detection of cystic
$(1976)$.

22. Wilson, G.B., and Fudenberg, H.H.: Studies on cystic fibrosis using isoelectric focusing. II. Demonstration of deficient proteolytic cleavage
of alpha 2 -macroglobulin in cystic fibrosis plasma. Pediat. Res., 10:87 (1976).

23. Wilson, G.B., and Fudenberg, H.H.: Further purification and char acterization of serum proteins used to detect cystic fibrosis
genotypes by isoelectric focusing. Tex. Rep. Biol. Med., 34:51 (1976).

24. Wilson, G.B., and Fudenberg, H.H.: Role of polyamines in the regulation of proteinase and proteinase-inhibitor function: Emphasis on an al pha 2 -macroglobulin-pol yamine defect in cystic fibrosis. in: R.A. Campell and G.D. Daves: Pacific
press (Raven Press, N.Y., 1977).

25. Wilson, G.B., and Fudenberg, H.H.: Pol yamines: Inhibition of alpha 2 -macroylobulin and proteol ytic enzymes. Relationship to the
pathophysiology of cystic fibrosis. Clin. Res.,25: in press (1977)

26. Wilson, G.B., and Fudenberg, H.H.: Ciliary dyskinesia factors in cystic fibrosis and asthma. Nature, in press (1977).

27. Wilson, G.B., Fudenberg, H.H., and Jahn, T.L.: Studies on cystic fibrosis using isoelectric focusing. I. An assay for detection of cystic fibrosis homozygotes and heterozygote carriers from serum. Pediat. Res., $9: 635$ (1975).

28. Wilson, G.B., and Jahn, T.L.: A comparative imaunological study of cystic fibrosis serum. III. A preliminary report on the kinetics and mode of action of cystic fibrosis serum on Colpidium striatum. in: Cystic Fibrosis Club Abstracts, p. 59 (Cystic Fibrosis Foundation, Atlanta. 1973).

29. Wilson, G.B., and Jahn, T.L.: Decreased rate of cytol ysis of Colpidium striatum by cystic fibrosis serum. I. Bioassay and evidence for the
possible involvement of a C/F factor-IgG complex. Life Sci.., 15:551, possib.

30. Wilson, G.B., Jahn, T.L., and Fonseca, J.R.: Demonstration of serun protein differences in cystic fibrosis by isoelectr ic focusing in thin-layer pol yacr ylamide gels. Clin. Chim. Acta, 49:79 (1973).

31. Wilson, G.B., Monsher, M.T., and Fudenberg, H.H.: Cystic fibrosis protein factor detected by isoelectric focusing and ciliary dyskinesia. Clin. Bes., 24:295 (1976).

32. Wilson, G.B., Monsher, M.T., and Fudenberg, H.H.: Additional notes on the use of analytical isoelectric focusing for the detection of cystic fibrosis protein in serum. Pediat. Res., 11: in press (1977).

33. Wilson, G.B., Monsher, M.T., and Fudenberg, H.H: Studies on cystic fibrosis using isoelectric focusing. III. Correlation between cystic fibrosis protein and ciliary dyskinesia activity in serum ahown by a
modified rabbit tracheal bioassay. Pediat. Res., 11: in press (1977).

34. Wilson, G.B., Monsher, M.T., and Fudenberg, H.H.: Distinction between ciliary dyskinesia activity (CDA) in leukocyte culture supernatants from
individuals with cystic fibrosis (CF) and asthma. Clin. Res., 25:34 (1977).

35. Wilson, G.B., Stites, D.P., and Fuclenberg, H.H.: The ciliary dyskinesia factors produced by leukocytes from individuals with cystic fibrosis an asthina are different substances. Nature, sucmitteo (19/7)

36. The authors gratefully acknowledge the cooperation of Margaret Jenkins, M.D. in obtaining blood specimens from patients at her clinic and Melvin T. Monsher and Judith A. Kenp for technical assistance. We thank Charles
L. Sinith for excellent editorial assistance. 
37. The research was aided in part by NIH Grants HD-09938 and AI-13484, by the South Carolina State Appropriation for Research A705 and by a Basi from the National Foundation - March of Dimes.

38. This is publication no. 76 from the Department of Basic and Clinical Imunology and Microbiology, Medical University of South Carolina.

39. Presented in part at the International Symposium on Electrofocusing and Annual Meeting of the Cystic Fibrosis Club, April 27, 1976, in St. Louis, Missouri.

4. Reguests for reprints should be addressed to: G.B. Wilson, Ph.D., Chateston 29481 (USA).

41. Received for publication November 9, 1976.

42. Accepted for publication January 19, 1977.

TABLE 1

CDA AND CFP IN HUMAN SERA

\begin{tabular}{lcll}
\hline Serum type & $\begin{array}{l}\text { Number } \\
\text { studied }\end{array}$ & CFpa & $\begin{array}{l}\text { Onset of Ciliary } \\
\text { dykinesia } \\
(\mathrm{min}) b\end{array}$ \\
\hline CF homozygote & 16 & + & $14 \pm 8$ \\
Obligate heterozygote & 15 & + & $25 \pm 8$ \\
Sibling of CF patient & 3 & - & $\mathrm{NR}$ \\
Normal individual & 4 & + & $19,24,29,35$ \\
Asthma & 13 & - & $\mathrm{NR}$ \\
& 1 & + & 20 \\
& 7 & - & $22 \pm 9$ \\
\hline
\end{tabular}

$a_{+}$, present; - , absent.

$b_{\text {Mean }} \pm$ S.D., NR, no reaction at $60 \mathrm{~min}$.

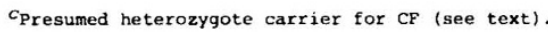

TABLE 3

CDA AND CFP IN FRACTIONS FROM SEPHADEX G200 GEL FILTRATION OF HUMAN SERA

\begin{tabular}{|c|c|c|c|c|c|c|}
\hline \multirow[t]{2}{*}{ Serum type } & \multicolumn{6}{|c|}{ CDA and CFP present in fractiona } \\
\hline & I & II & III & IV & $v$ & vI \\
\hline Norma 1 & - & - & - & - & - & - \\
\hline Normal-EDTA ${ }^{b}$ & - & - & - & - & - & $\mathrm{CDA}$ \\
\hline CF homozygote & - & - & $\begin{array}{l}\text { CFP/ } \\
\text { CDA }\end{array}$ & $\mathrm{CDA}$ & - & - \\
\hline CF homozygote-EDTA ${ }^{b}$ & - & - & - & - & - & $\begin{array}{l}\text { CFP/ } \\
\text { CDA }\end{array}$ \\
\hline Heterozygote & - & - & $\begin{array}{l}\text { CFP/ } \\
\text { CDA }\end{array}$ & $\mathrm{CDA}$ & - & - \\
\hline Heterozygote-EDTA ${ }^{b}$ & - & - & - & - & - & $\begin{array}{l}\text { CFP/ } \\
\text { CDA }\end{array}$ \\
\hline Asthmatic & - & $\mathrm{CDA}$ & - & - & - & - \\
\hline Asthmatic-EDTA ${ }^{b}$ & - & - & - & - & - & $\mathrm{CDA}$ \\
\hline Asthmatic/heterozygote ${ }^{c}$ & - & CDA & $\begin{array}{l}\text { CFP/ } \\
\text { CDA }\end{array}$ & $\operatorname{CDA}$ & - & - \\
\hline Asthmatic/heterozygote-EDTA ${ }^{b}$ & - & - & - & - & - & $\begin{array}{l}\text { CFP/ } \\
\text { CDA }\end{array}$ \\
\hline
\end{tabular}

${ }^{a}$ CFP and CDA positivity as defined in Table 2.

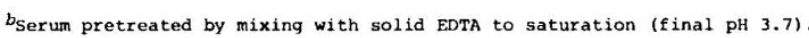

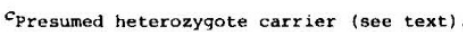

TABLE 2

CDA AND CFP IN FRACTIONS FROM DEAE-CELLULOSE CHROMATOGRAPHY OF HUMAN SERA

\begin{tabular}{|c|c|c|c|c|c|c|c|c|}
\hline \multirow[t]{3}{*}{ Serum type ${ }^{a}$} & \multicolumn{8}{|c|}{ CDA and CFP present in fraction } \\
\hline & \multicolumn{4}{|c|}{$\begin{array}{l}0.01 \mathrm{M} \text { phosphate } \\
\text { buffer (pH } 8.0)\end{array}$} & \multicolumn{4}{|c|}{$\begin{array}{l}0.005 \mathrm{M} \text { Tris-HCl } \\
\text { buffer (pH 8.6) }\end{array}$} \\
\hline & $\begin{array}{c}I^{b} \\
(0.0)^{c}\end{array}$ & $\begin{array}{c}\text { II } \\
(0.05)^{c}\end{array}$ & $\begin{array}{l}\operatorname{III} \\
(0.1) \mathrm{C}\end{array}$ & $\begin{array}{l}\text { IV } \\
(0.2)^{C}\end{array}$ & $\begin{array}{c}I^{b} \\
(0.0)^{c}\end{array}$ & $\begin{array}{c}\mathrm{II}^{b} \\
(0.05)^{c}\end{array}$ & $\begin{array}{l}\operatorname{III} \\
(0.1)^{C}\end{array}$ & $\begin{array}{l}\text { IV } \\
(0.2)\end{array}$ \\
\hline Norma 1 (CFP-, $\mathrm{CDA}-$ ) & - & - & - & - & - & - & - & - \\
\hline $\begin{array}{l}\text { CF homozygote } \\
\text { (CFPt, CDA+) }\end{array}$ & $\begin{array}{l}\text { CFP/ } \\
\text { CDA }\end{array}$ & - & - & - & $\begin{array}{l}\mathrm{CFP} / \\
\mathrm{CDA}\end{array}$ & - & - & - \\
\hline Obligate heterozygote & $\begin{array}{l}\text { CFP/ } \\
\mathrm{CDA}\end{array}$ & - & - & - & $\begin{array}{l}\mathrm{CFP} / \\
\mathrm{CDA}\end{array}$ & - & - & - \\
\hline Asthmatic (CFP-, $\mathrm{CDA}+)$ & $\mathrm{CDA}$ & - & - & - & - & $\mathrm{CDA}$ & - & - \\
\hline $\begin{array}{l}\text { Asthmatic Meterozygote } \\
\text { (CFP+, CDA+) }\end{array}$ & $\begin{array}{l}\text { CFP/ } \\
\mathrm{CDA}\end{array}$ & - & - & - & $\begin{array}{l}\text { CFP/ } \\
\text { CDA }\end{array}$ & $\mathrm{CDA}$ & - & - \\
\hline
\end{tabular}

asera and fractions are indicated as being cystic fibrosis protein (CFP) positive as determined by electrofocusing, and as having ciliary dyskinesia activity (CDA) as determined by the rabbit tracheal bioassay. Sera and fractions noted as CDA positive produced ciliary dyskinesia by $35 \mathrm{~min}$.

bractions containing IgG as determined by imnunoelectrophoresis.

cMolarity of $\mathrm{NaCl}$ used for elution.

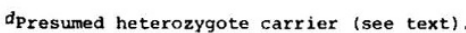

TABts 4

CDA IN SUBFRACTIONS FROM BIO-GET PIO FILTRATION OF ACTIVE FRACTIONS

\begin{tabular}{|c|c|c|c|c|c|c|c|}
\hline \multirow[t]{2}{*}{ Sample } & \multicolumn{7}{|c|}{ CDA present in subfraction ${ }^{a}$} \\
\hline & A & I & II & III & IV & $\mathrm{v}$ & vI \\
\hline CF-EDTA G200 Fr.vI ${ }^{b}$ & $\mathrm{NP}$ & CDA & - & CDA & $\mathrm{CDA}$ & CDA & - \\
\hline Normal-EDTA G200 Fr.vI ${ }^{b}$ & $\mathrm{NP}$ & $\operatorname{CDA}( \pm)$ & - & - & - & $\mathrm{CDA}$ & - \\
\hline $\begin{array}{l}\text { Heterozygote-EDTA } \\
\qquad \text { G200 FR.VI }{ }^{b}\end{array}$ & NP & $\mathrm{CDA}$ & - & $\mathrm{CDA}$ & $\mathrm{CDA}$ & $\mathrm{CDA}$ & - \\
\hline Asthma-EDTA G200 Fr. $\mathrm{VI}^{b}$ & $\mathrm{NP}$ & $\mathrm{CDA}$ & - & - & - & $\mathrm{CDA}$ & - \\
\hline Asthma G200 Fr.II & $\mathrm{CDA}$ & - & - & - & - & - & - \\
\hline Asthma G200 Fr.II-EDTAC & - & $\mathrm{CDA}$ & - & - & - & - & - \\
\hline Normal G200 Fr.II-EDTA ${ }^{C}$ & - & $\mathrm{CDA}$ & - & - & - & - & - \\
\hline CF G200 Fr.III, IV & $\mathrm{CDA}$ & - & - & - & - & - & - \\
\hline CF G200 Fr.III, IV-EDTA ${ }^{C}$ & - & $\operatorname{CDA}$ & - & $\mathrm{CDA}$ & $\mathrm{CDA}$ & - & - \\
\hline Normal G200 Fr. III, IV-EDTA ${ }^{C}$ & - & $\mathrm{CDA}$ & - & - & - & $\operatorname{CDA}( \pm)$ & - \\
\hline CF IgG & $\mathrm{CDA}$ & - & - & $\operatorname{CDA}( \pm)$ & - & - & - \\
\hline CF IgG-EDTA ${ }^{C}$ & - & $\mathrm{CDA}$ & - & $\operatorname{CDA}$ & $\mathrm{CDA}$ & - & - \\
\hline
\end{tabular}

$a_{N P}$, no peak; $C D A$ as defined in Table $2, \operatorname{CDA}( \pm)$, weak activity. Subfractions were $2 \mathrm{X}$ concentrated before testing.

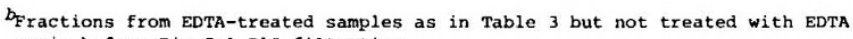
again before Bio-Gel Plo filtration.

cSample pretreated by mixing with solid EDTA to saturation (final pH 3.7) before Bio-Gel P10 filtration. 
TABLE 5

RELATIVE PURIFICATION OF CILIARY DYSKINESIA ACTIVITIES IN CF OR ASTHMATIC SERA

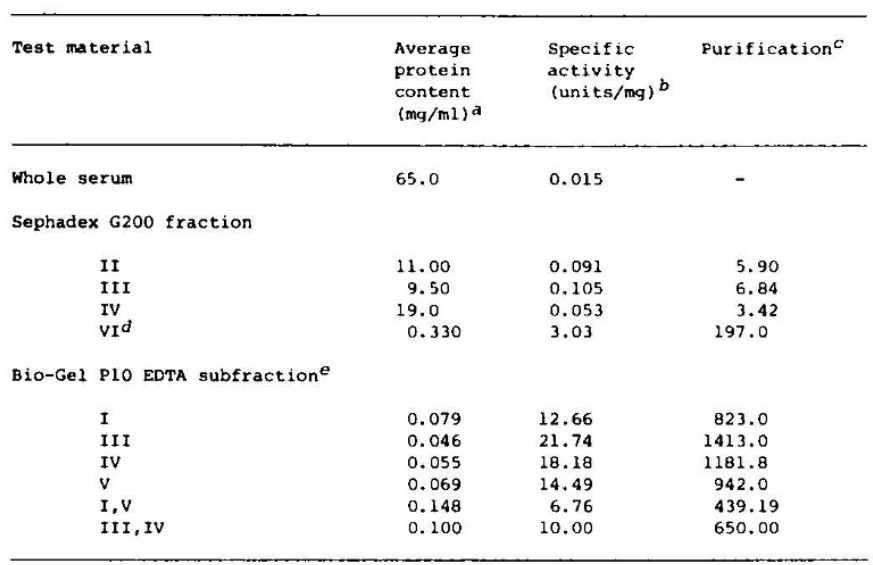

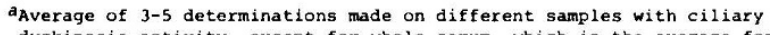
dyskinesia activity, except for whole serum, which is the average for 6 active samples ( 3 asthma, 3 CF homozygote).

$b_{O n e}$ unit is defined as the reciprocal of the protein content in a $1 \mathrm{X}$ concentrated fraction that shows activity no later than $35 \mathrm{~min}$ (assuming that the entire protein content is required for activityl.

cpurification of activity relative to whole serum (assuming that there is no loss of activity).

$d_{\text {Fraction obtained from EDTA-treated serum. }}$

esubfractions obtained from Sephadex G200 Fr.VI of active preparations of EDTA-treated asthma or CF homozygote sera.

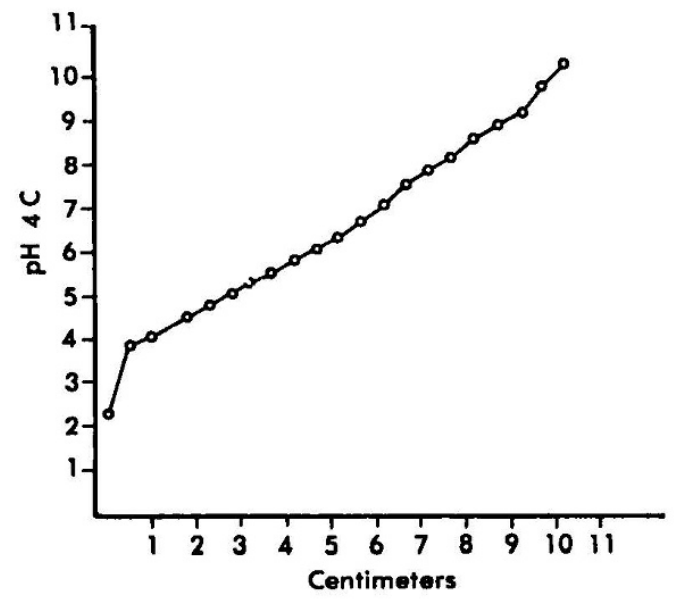
Fig. 1. Results of $\mathrm{pH}$ measurement at $4^{\circ} \mathrm{C}$ from anode to cathode on the
surface of a polyacrylamide gel similar to the one in Figure 2. Abscissa, centimeters from the anode.

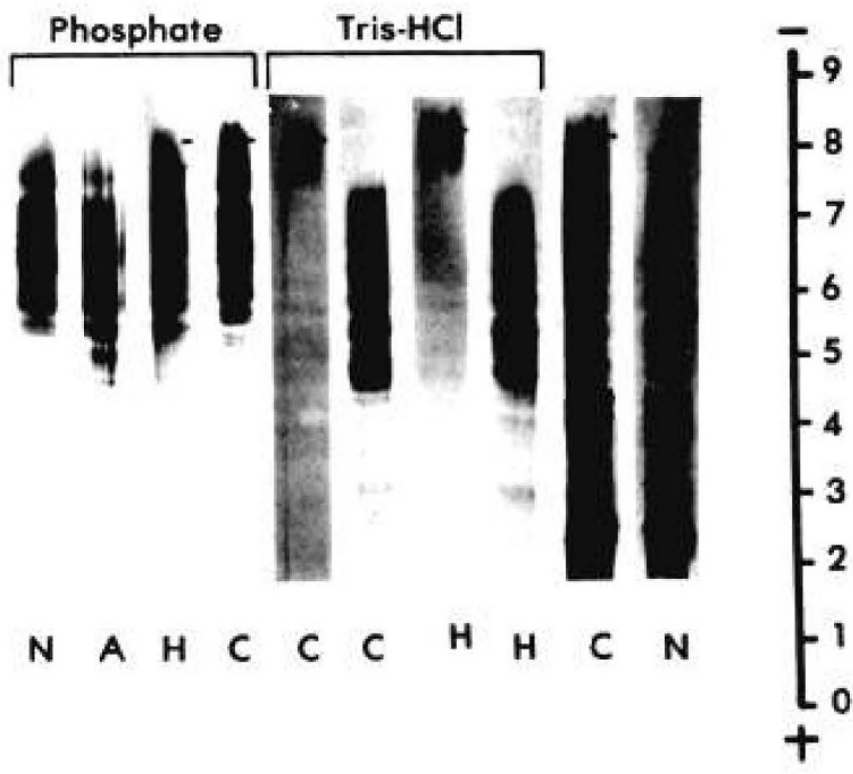

Fig. 2. Results of electrofocusing on the LKB Multiphor (pH 2.5-10) of serum fractions obtained from DEAE-cellulose chromatography using phosphate buffer, $\mathrm{pH} 8.0$ (phosphate), or Tris-HC1 buffer, $\mathrm{pH} \mathbf{8 . 6}$ zygote, and asthmatic sera respectively, left to right, Fraction obtained after DEAE-cellulose chromatography of $\mathrm{N}$, A, H, or C sera using phosphate buffer; Fraction I and II from DEAE-cellulose chromatography of $\mathrm{C}$ and $\mathrm{H}$ serum respectively using $\mathrm{Tr}$ is- $\mathrm{HCl}$ buffer whole CF and normal sera. All serum samples and DEAE-cellulose samples contained $300 \mathrm{\mu g}$ of IgG. See Table 2 for definition of fractions. Line indicates location of cystic fibrosis protein (CFP). A scale (right) shows the distance in centimeters from . tom of the sample application pad $10.5 \mathrm{~cm}$ from the anode).

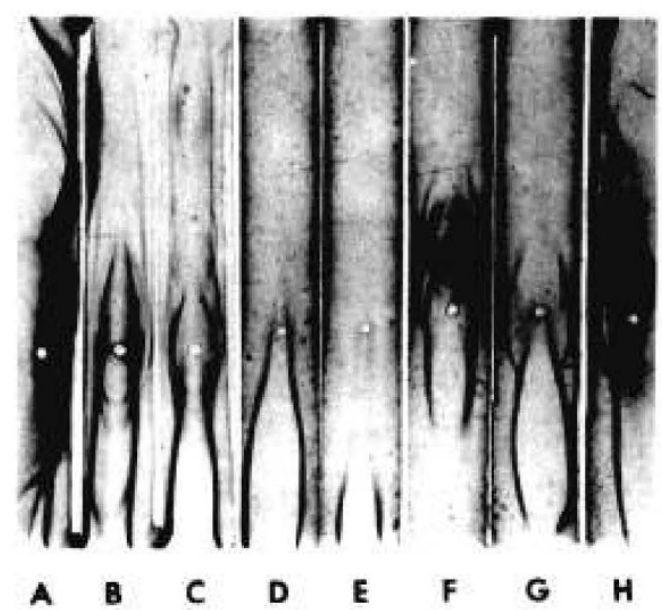

Fig. 3. Analysis of whole serum and fractions obtained from Sephadex 6200 gel filtration and DEAE-cellulose chromatography by immunoelectrowhole normal human serum. (a) Whole serum. (b) Sephadex G200 Fraction II. (c) Sephadex G200 Fraction III. (d) DEAE-cellulose Fraction I, phosphate buffer. (e) DEAE-cellulose Fraction I, Tris-HCl buffer. (f) DEAE-cellulose Fraction II, phosphate buffer. (g) DEAE-cellulose Fraction II, Tris-HCl buffer. (h) Whole serum. See Tables 2 and 3 for definition of fractions from DEAE-cellulose chromatography and Sephadex G200 gel filtration. 


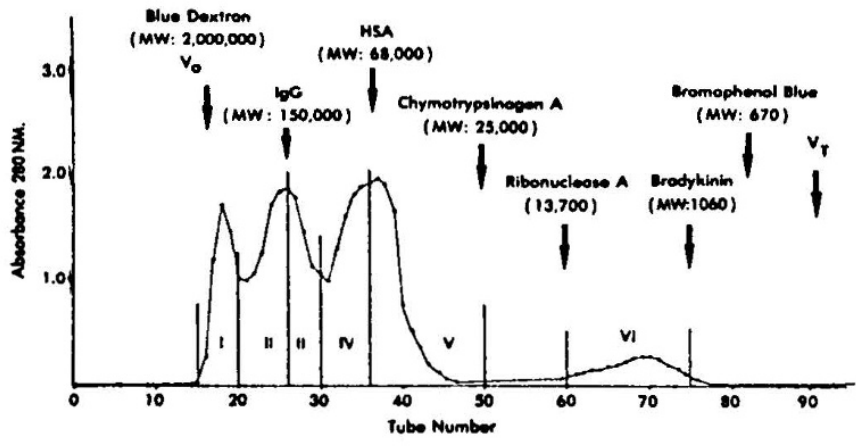

Fig. 4. Typical chromatogram obtained by fractionation of $2.0 \mathrm{ml}$ of serum on Sephadex G200. HSA, human serum albumin; $\mathrm{V}_{0}, \mathrm{~V}_{\mathrm{T}}$, void volume with reqular or EDTA-treated sera.

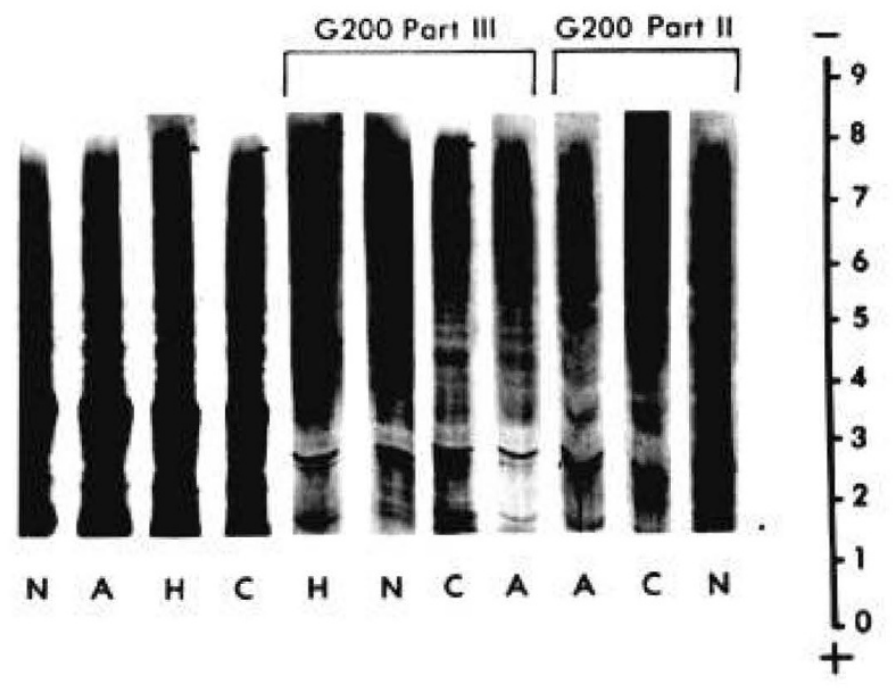

Fig. 5. Results of electrofocusing on the LKB Multiphor of Sephadex G200 Fractions II and III from untreated sera. Left to right, whole $N$, A, H, and C sera; G200 Fraction III from N, H, C, or A sera; G200 Fraction II from A, C, or $\mathrm{N}$ sera. A, C, N, H, and scale as defined in Figure 2.

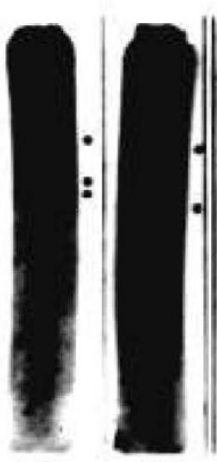

H

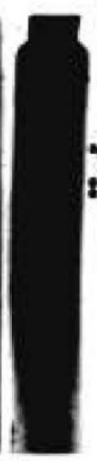

C

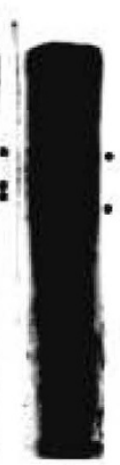

A -
Fig. 6. Disc gel electrophoresis of Fraction VI from Sephadex G200 ge1 filtration of untreated sera. Dots depict cathodally migrating bands of interest. $\mathrm{H}, \mathrm{N}, \mathrm{C}$, and $\mathrm{A}$ as in Figure 2 . Note presence of extra cathodal migrating bands in $\mathrm{H}$ and C G200 Fraction VI. Each sample contained $25 \mu \mathrm{g}$ protein.

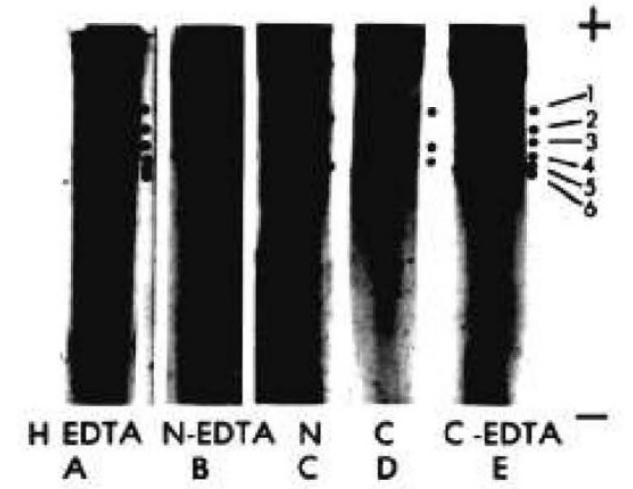

Fig. 7. Disc gel electraphoresis of Fraction VI from Sephadex G200 ge1 filtration of EDTA-treated sera. Dots depict six bands of interest. G200 Fractions VI from $H_{2} N$ and $C$ sera $(a, b, e)$ to facilitate direct comparison of the results. Wote the occurrence of additional cathodal bands (bands 4,5 , and 61 in samples a and e as compared with $b, c$, and $d$. Each sample contained 25 Hg of protein, except for $e$, which contaned 35 ug.

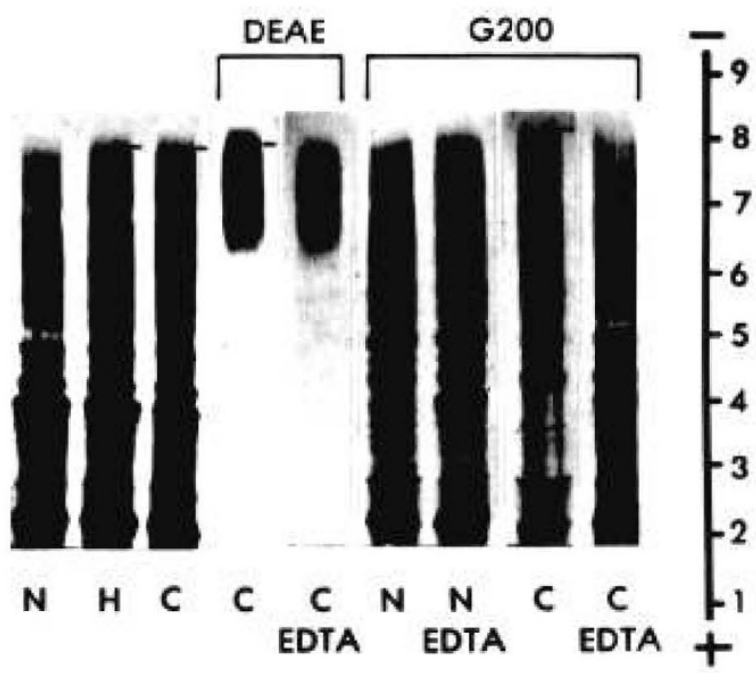

Fig. 8. Effect of EDTA treatment on serum positivity for CFP as shown by electrofocusing on the LKB Multiphor $(\mathrm{pH} 2.5-10)$. Left to right, whole $\mathrm{N}, \mathrm{H}$, and C sera; Fraction A from Bio-Gel PlO filtration of CF DEAE-cellulose Fraction I (Tris-HCl) without and with prior treatment with EDTA (C and C-EDTA); Sephadex G200 Fraction III from $N$ or $C$ sera without or with prior treatment with EDTA. Scale as in Figure 2 .

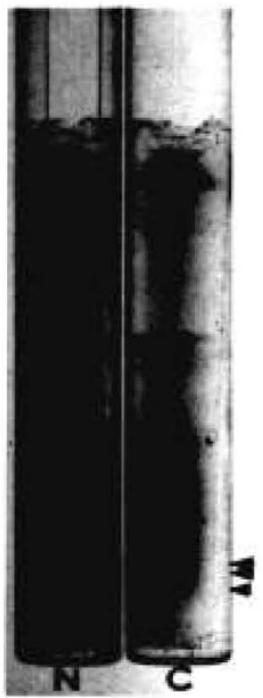

Fig. 9. Results of disc gel electrophoresis of G200 Fraction vi from EDTAtreated CF or normal serum ( $25 \mu \mathrm{g})$. Arrows mark cathodal bands with pIs near pH 8.5. Note that the normal sample fails to show these bands, even though the intensity of bannding elsewhere in the gel is similar. 


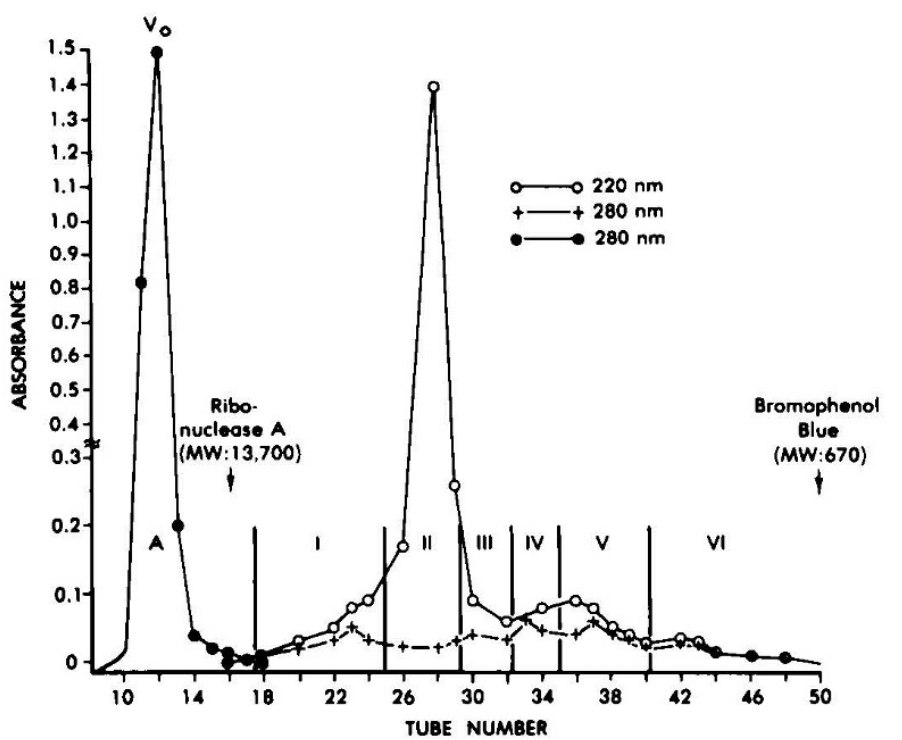

Fig. 10. Composite chromatogram for elution of Sephadex G200 or DEAE-

cellulose (Tris-HCl) fractions on Bio-Gel P1O. Fractions of $2.0 \mathrm{ml}$

were collected. Absorbance was recorded at $220 \mathrm{~nm}$ or $280 \mathrm{~nm}$ as
indicated. $v_{0}$ as in Figure 4. See Table 4 and text for details.

324 